\title{
EUROPEAN AUTOMATED CONTAINER TERMINALS
}

The establishment of the container as a cargo packaging unit belongs to the most significant developments in maritime transport in the 20 th century. Containers started to be used in sea transport due to the reduction of loading time. They also protect cargo against its damage, theft and loss [1]. Containers are transported by specialized cellular container ships that are classified into the generations depending on their size. The role of the container terminals is to handle, load, unload, and transfer containers by special equipment. There is also a yard where containers are stored [2] and [3]. Congested container sea ports have implemented new ways how to increase their throughput. The construction of automated container terminals is one way how to do it.

Keywords: Automated container terminal, automated guided vehicles, automated stacking cranes.

\section{Introduction}

Container terminals are facilities where containers are loaded, unloaded, handled, and transferred by different type of container handling equipment between different means of transport. They are also stored in an open-air storage area for a few days before they are forwarded by sea or land transport to their customers [2].

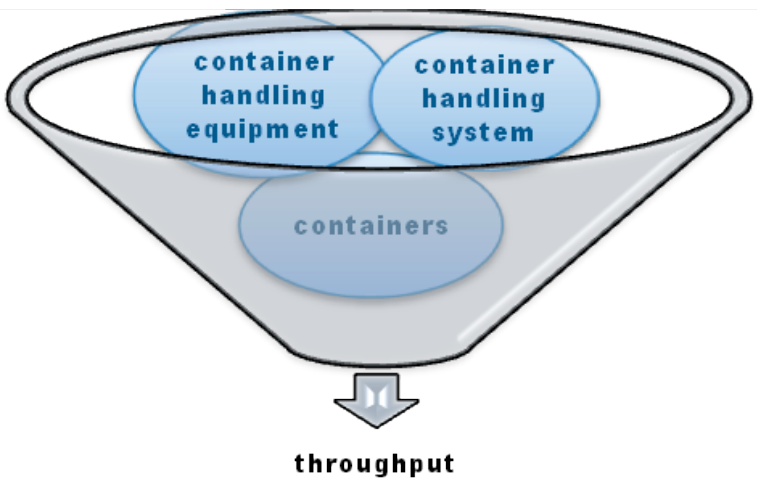

Fig. 1 The factors that influence the throughput of the container terminals

Source: authors

The throughput belongs to the most important indicators of the container terminals. It may be defined as the number of containers that are transferred by handling equipment for the monitoring period. It depends on the types of:

- container vessels that sail into the terminal,

- containers,
- container handling equipment,

- container handling systems (see Fig. 1).

The various downtimes that decrease the throughput of the terminals arise during handling of containers. They follow from the breakdown rate and technical breaks of container handling equipment, auxiliary operations that are related to the vessels such as anchoring and inspection of vessels controls of the documents or containers [4].

The container sea ports have implemented various ways how to increase their throughput, such as:

- to increase the number of gantry container cranes that serve container ships,

- to increase the number of trolleys of cranes and their travelling velocities,

- to modify spreaders of cranes that may lift at least 2 containers in one operating cycle such as twin lift container spreaders (Fig. 2), double or triple spreaders,

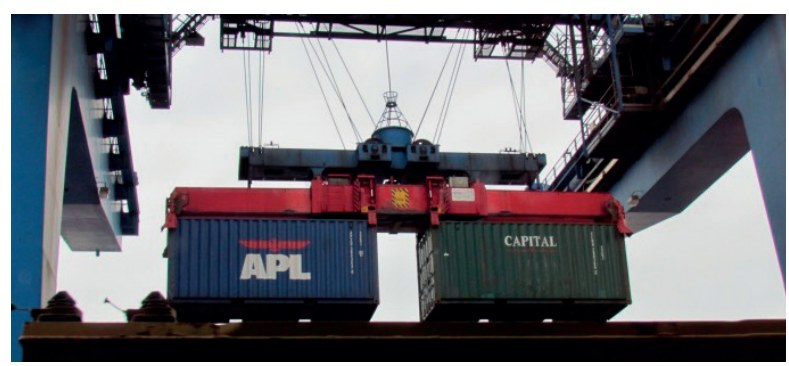

Fig. 2 Twin-lift spreader

Source: authors

\footnotetext{
* ${ }^{1}$ Andrej David, ${ }^{1}$ Jarmila Sosedova, ${ }^{2}$ Lisa-Maria Putz, ${ }^{3}$ Natalija Jolic, ${ }^{3}$ Zvonko Kavran

${ }^{1}$ University of Zilina, Slovakia, Faculty of Operation and Economics of Transport and Communications, Department of Water Transport,

E-mail: andrej.david@fpedas.uniza.sk

${ }^{2}$ University of Applied Sciences Upper Austria, Faculty of Management Steyr, Department for Logistics and Transport, Austria

${ }^{3}$ University of Zagreb, Faculty of Transport and Traffic Sciences, Department of Water Transport, Croatia
} 
- to automate handling systems in the container terminals [5] and [6].

\section{Container handling equipment}

Container handling equipment can be divided into two categories:

1. Equipment that moves containers between the vessel and the terminal such as gantry container cranes. These cranes belong to the most widespread equipment in the world container sea ports. They can serve specialized container vessels that anchor at the wharf.

2. Equipment that moves containers within the terminal. Various equipment types are used for handling of containers within the terminal. Straddle carriers, automated guided vehicles or tractors towing trailers transfer containers between the wharf and the container yard. Within the terminal straddle carriers, rubber-tired or rail-mounted gantry cranes can carry out stacking or unstacking of containers. Tractor-trailer systems may be involved in receipt-delivery operations [2].

\subsection{Gantry container cranes}

Gantry container cranes are the most characteristic feature of the container terminals. They transship containers between the container ship and the terminal. The latest cranes have their outreach more than $60 \mathrm{~m}$. They can serve vessels that have more than 22 rows of containers on deck. The time for one operating cycle is about two minutes. They can transfer about 30 containers per hour and some of them can handle more than 30 containers per hour [2]. They have to be equipped with double twin-lift spreaders that can lift four 20 's containers or two 40 's in one operating cycle. The throughput of a crane depends on:

- the number of containers that are handled in one operating cycle,

- the time for one operating cycle,

- the speed of a trolley,

- the position of containers on the container ship.

\subsection{Straddle carriers}

Straddle carriers are the most popular type of container handling equipment. They have a wheeled frame that lifts and transports containers within its framework. They can stack containers up to 3 tiers [2].

\subsection{Rubber-tired gantry cranes}

Rubber-tired gantry cranes run on heavy duty pneumatic-tired wheels. They are container-yard stacking device and are used in the combination with other container handling equipment (tractor-trailer set) for the wharf transfer operation. They handle containers within the block that is parallel to the wharf. They can also move from one block to another. These cranes are used mainly in Asian and American terminals [2].

\subsection{Rail-mounted gantry cranes}

Rail-mounted gantry cranes run on steel wheels over fixed rails. They are similar to rubber-tired gantry cranes in the function. They are used in the combination with tractor-trailer sets for wharf transfer operation. In the container terminals two types of cranes are used. The first type of cranes is used for stacking of containers in the blocks of the container yard that are perpendicular to the wharf. The second type of cranes is used on receipt and delivery operations at rail terminal. They usually have large spans and may stack containers up to 6 tiers. Both cranes are used mainly in automated container terminals [2].

\section{Automated container terminals}

Automated container terminals are defined as terminals with some container handling equipment operating without direct human interaction. In most cases, drivers have been physically removed from the cranes. In some cases drivers remain in the equipment cabins but are not needed for the entire duty cycle [7]. Automated container terminals use automated guided vehicles, automated stacking cranes and rail-mounted gantry cranes in their handling systems.

\section{Automated container terminals in the European sea ports}

\subsection{Port of Rotterdam and its automated container terminals}

The port of Rotterdam (Fig. 3) that is the largest sea port in Europe is the gateway for cargo transported from Asia or America. It is located on the banks of the Nieuwe Mass (one of the distributaries of the Rhine River) and the coasts of the North Sea. It is also the largest container sea port in Europe. About 11.87 mil. TEUs were transferred in the port in 2012 [8] and [9].

The container terminals are located in different parts of the port such as Maasvlakte 1, 2, Eemhaven or Waalhaven. They are divided according to the size of container ships. The latest generation of container ships (Ultra Large Container Ships) or bulk carriers can sail only into the parts Maasvlakte 1 and 2 due to their draught. These parts are located near the estuary of the Nieuwe Mass into the North Sea. On the other hand smaller 
container ships can also sail into the parts of the port that are located more than $30 \mathrm{~km}$ from the North Sea in the city centre. These ships transport containers to the United Kingdom or Scandinavia.

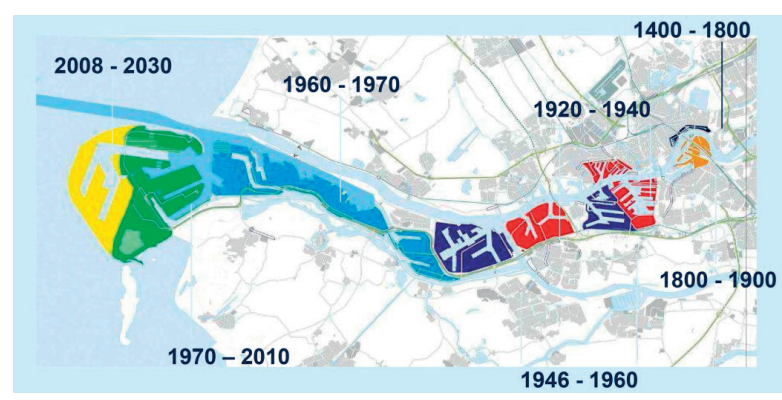

Fig. 3 The development of the port of Rotterdam Source: port of Rotterdam

Maasvlakte 1 started to be built in the middle of the 1960s. It was the first time that the land was reclaimed from the North Sea for the port. In the 1980 s the container terminal operator European Container Terminals (ECT) built its terminal ECT Delta (Fig. 4). It was the first European automated container terminal that started using the system of automated guided vehicles in 1992. The handling system consists of gantry container cranes, automated guided vehicles, automated stacking cranes on rails, straddle carriers and semitrailers. Gantry container cranes transship containers between the container ship and automated guided vehicles. These vehicles transport containers between the wharf and the container yard that is divided into the blocks according to type of containers and their final destinations, cargo that is loaded into containers. Each block is equipped with one automated stacking crane that transfers containers between automated guided vehicles and this block. It also manipulates containers within the block. Straddle carriers handle containers between the blocks of the container yard and semitrailers. In the terminal there is also a railway station where containers are loaded on the wagons by rail-mounted gantry cranes and are transported to the hinterland [10].

Euromax Terminal Rotterdam (Fig. 5) is another automated terminal in Maasvlakte 1. It started its operation in 2008. Handling system of this terminal is similar to ECT Delta Terminal. Gantry container cranes can also serve the latest generation of container ships with 22 rows of containers on deck. The basic difference is that each block is equipped with two automated stacking cranes. The first crane transfers containers between automated guided vehicle and the block of the container yard, the second crane transships containers between the block of the container yard and semitrailer. In the land side of the terminal there is also a railway station where containers are loaded on the wagons [10].

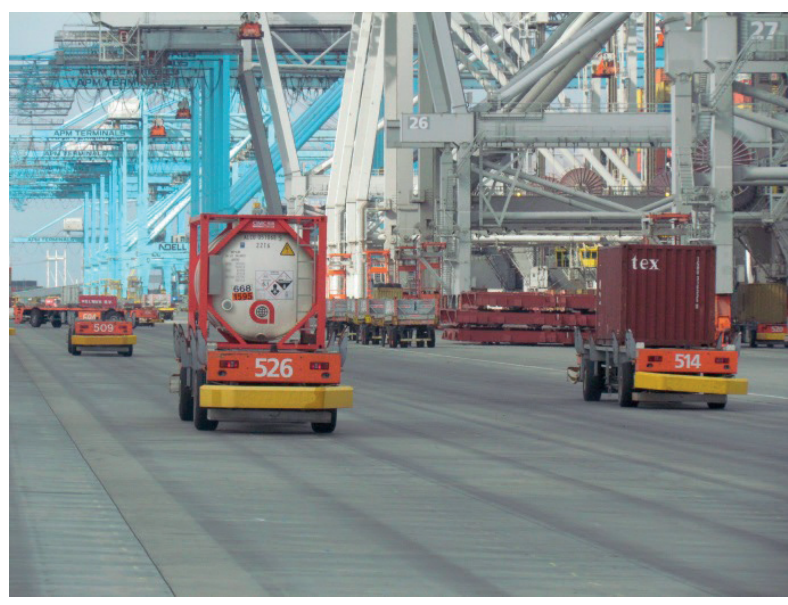

Fig. 4 Automated guided vehicles in ECT Delta Terminal Source: authors

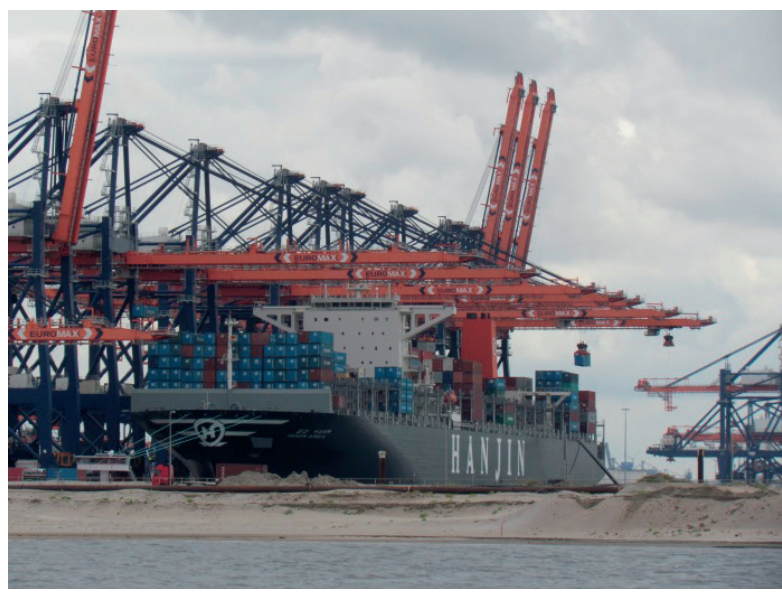

Fig. 5 Transfer of containers in Euromax Terminal Rotterdam Source: authors

Maasvlakte 2 is a new part of the port of Rotterdam. It was the second time in the history of the port that the port spread out its land to the North Sea due to no room for its further development.

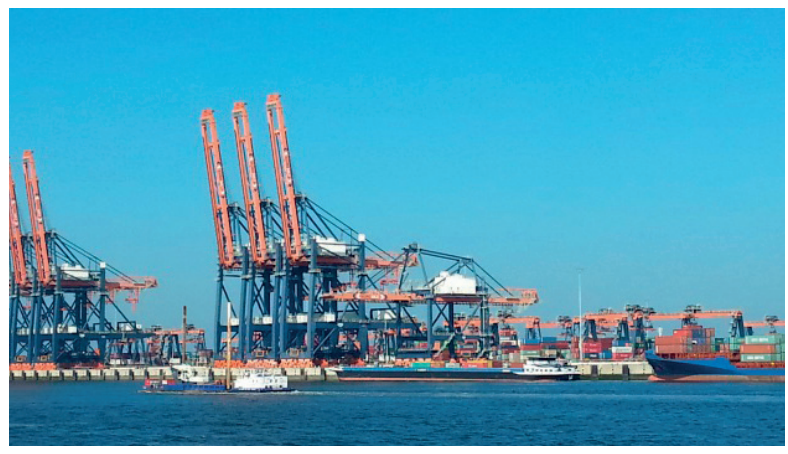

Fig. 6 Maasvlakte 2

Source: authors 
The construction of Maasvlakte 2 (Fig. 6) was started in 2008. About 240 million $\mathrm{m}^{3}$ of sand was required for its construction; most of it came from the North Sea. After opening Maasvlakte 2 in May 2013 the port of Rotterdam widened its land about $20 \%$ (2 000 hectares). New container terminals (APM Terminals and Rotterdam World Gateway) will be opened there in 2014 [9].

\subsection{Automated container terminals in the European sea ports}

The port of Hamburg is the second important container port in Europe. In 2012 it handled about 8.86 mil. TEUs [8]. It is located on the banks of the Elbe River. In the port there are four container terminals, two of them are automated terminals: the Container Terminal Altenwerder (CTA) and the Container Terminal Burchardai (CTB).

At present the Container Terminal Altenwerder is one of the most modern terminals in the world. It was put in operation in 2002. The total costs for its construction were about 650 million EUR, of which 300 million EUR were spent for the construction of quay and infrastructure [11]. It is located in the southern part of Hamburg. Four Post-Panamax ships can anchor at the wharf that is $1400 \mathrm{~m}$ long. The handling system of CTA consists of gantry container cranes, automated guided vehicles, automated stacking cranes on rails and semitrailers. Gantry container cranes that transship containers between the ship and the terminal can serve container vessels Post-Panamax. They have two trolleys. The first trolley (water side trolley) drops containers on the platform that is situated inside of the crane portal. The second trolley (land side trolley) loads containers on automated guided vehicles (Fig. 7) that transport containers to the block of the container yard. Each block is equipped with two automated stacking cranes or rail with the different gauge. The first one transfers containers between automated guided vehicle and the block of the container yard. The second one transfers containers between the block of the container yard and semitrailer. In the land side there is also a railway station where containers are handled by rail mounted gantry cranes between semitrailers and wagons [11] and [12].

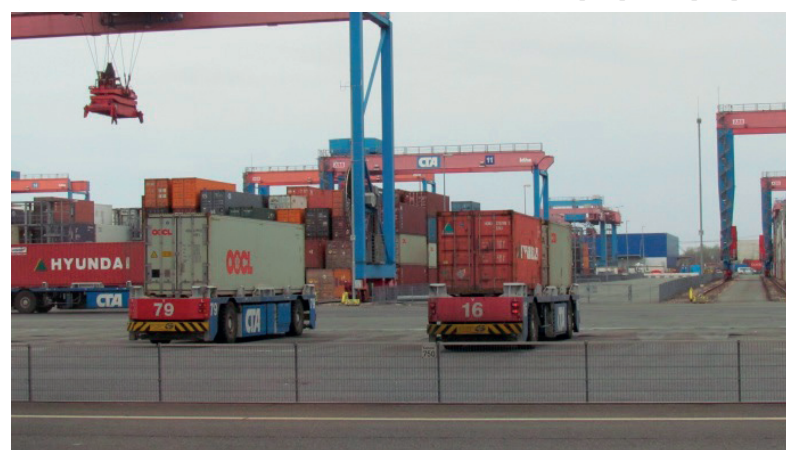

Fig. 7 Automated guided vehicles in CTA Source: authors
Container Terminal Burchardkai (Fig. 8) is the oldest and largest container terminal in the port of Hamburg. The first containers were transferred in this terminal in 1968. Ten PostPanamax container ships can anchor at the wharf that is $2850 \mathrm{~m}$ long. The handling system of the terminal consists of straddle carriers that handle containers between gantry container cranes and the blocks of the container yard. It is one of the oldest systems used in the terminals. At the moment this terminal is being reconstructed. New generation of gantry container cranes will be equipped with double spreaders. They will be able to lift four 20 's containers or two 40's in one operating cycle. Straddle carriers will handle containers between gantry container cranes and the blocks of the container yard. Each block will be equipped with three automated stacking cranes on rail with the different gauge. Two of them will be smaller, one of them will be bigger. The first smaller automated stacking crane will transfer containers between straddle carriers and the block of the container yard, the second one will transfer containers between the block of the container yard and semitrailers. Bigger automated stacking crane will handle containers within the block. This construction will be completed in 2015 [11] and [12].

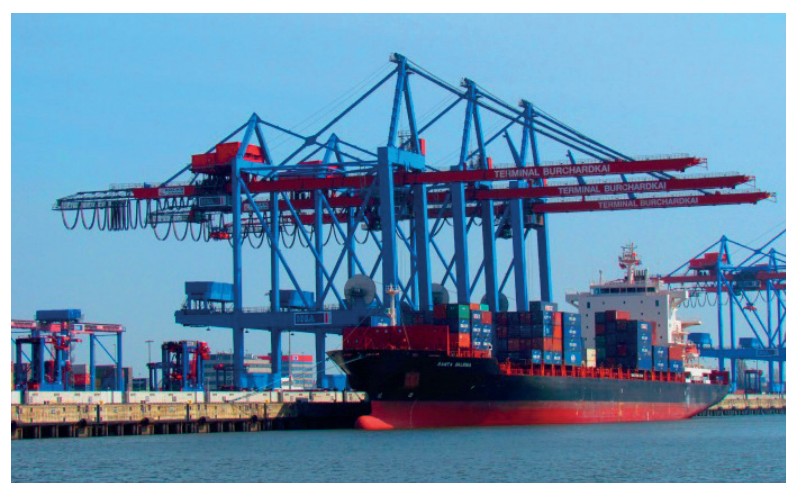

Fig. 8 Container Terminal Burchardkai

Source: authors

\section{Conclusion}

Between 1990 and 2010 the volume of containers that was handled in the container sea ports increased four times. One way how to increase the throughput in the congested container terminals is to automate their handling systems. Rubber tyre gantry cranes, straddle carriers or semitrailers have been replaced by automated handling equipment such as automated guided vehicles or automated stacking cranes on rails. Their movement is managed by the software [13]. In Europe there are only a few automated container terminals. Although the costs of the construction of these terminals are several times higher, their higher throughput, the automation of handling processes, the reduction of port workers including the staff costs have become the most important factors for their constructions. 


\section{References}

[1] STOPFORD, M.: Maritime Economics. Routledge, Oxon 2009, 816 pp., ISBN 978-0-415-27558-3.

[2] TSINKER, G.: Port Engineering. John Wiley and Sons, New Jersey 2004.

[3] AGERSHOU, H.: Planning and Design of Ports and Marine Terminals. Thomas Telford Publishing, London 2004, 450 pp., ISBN 978-07277-3498-3.

[4] ZALEZAK, M.: Technology in Ports and Transshipment Areas, 8 - Container Terminals. EDIS - the editor of the University of Zilina, 2001, ISBN 80-7100-867-2.

[5] DAVID, A.: Innovation of Handling Systems in the World Container Ports and Their Terminals. Proc. of $17^{\text {th }}$ Intern. Conference: Transport Means 2013, Kaunas University of Technology, Lithuania, 2013, pp. 250-253, ISSN 1822-296 X.

[6] SIROKY, J.: Progressive Systems in Combined Transport. Pardubice University, 2010, p. 184. ISBN 978-80-86530-60-4.

[7] Port of Los Angeles Automated Container Terminal Survey, Oakland 2012.

[8] Top 50 World Container ports, online: http://www.worldshipping.org/about-the-industry/global-trade/top-50-world-container-ports, November 2013.

[9] Port of Rotterdam, online: http://www.portofrotterdam.com/, 20 November 2013.

[10] European Container Terminals, online: http://www.ect.nl, 20 November 2013.

[11] Container terminal Altenwerder, online: http://www.svazdopravy.cz/html/cz/ cta.pdf, 20 November 2013.

[12] Hamburger Hafen und Logistik, online: www.hhla.de, 20 November 2013.

[13] SOSEDOVA, J., SLESINGER, M., BARIAK, M.: Telematics in Inland Navigation. Communications - Scientific Letters of the University of Zilina, vol. 12, No. 3, 2008, EDIS-ZU Zilina, pp. 66-68, ISSN 1335-4205. 